\title{
Entre luz e sombras: o processo de criação do espetáculo Segredos e Sombras
}

\author{
Between light and shadows: the \\ composing process of the spectacle \\ Secrets and Shadows
}

Saulo Germano Sales Dallago ${ }^{1}$

Wesley Martins da Silva ${ }^{2}$

Francisco Guilherme Oliveira Júnior ${ }^{3}$ 


\section{Resumo}

Este trabalho objetiva descrever as etapas do processo de criação do espetáculo Segredos e Sombras, produzido em Goiânia (GO) no ano de 2017, abordando a utilização da iluminação cênica, do teatro de sombras e da projeção audiovisual como componentes estéticos desta montagem. Buscando teorias acerca do design de luz para a cena e do teatro de sombras contemporâneo, a pesquisa demonstra desafios e descobertas na trajetória de elaboração da peça, adaptada a partir do conto $A$ Causa Secreta, de Machado de Assis, além de novas perspectivas de auto iluminação, projeção e controle de sombras não intencionais na cena advindas a partir da segunda temporada do espetáculo, em 2019.

Palavras-chaves: Teatro; teatro de sombras; iluminação cênica; audiovisua

\section{Abstract}

This paper aims to describe the stages of the process of creating the show Secrets and Shadows, produced in Goiânia (GO) in 2017, addressing the use of scenic lighting design, shadow theatre and audiovisual projection as aesthetic components of this montage. Seeking theories about light design for the scene and contemporary shadow theater, the research demonstrates challenges and discoveries in the course of the elaboration of the piece, adapted from Machado de Assis tale's "The secret cause", as well as the new perspectives of self-lighting, projection and control of unintentional shadows in the scene starting in second season of the show, in 2019.

Keywords: Theatre; shadow theatre; scenic lighting; audio-visual

E-ISSN: 2358.6958

\footnotetext{
1 Prof. Dr. Curso de Teatro/Licenciatura (presencial e EAD) e Direção de Arte/Bacharelado - Universidade Federal de Goiás (GO). sauloator@uol.com.br

${ }^{2}$ Doutorando da Universidade Federal de Goiás (UFG) - Programa de Pós-Graduação em Performances Culturais e Técnico em Audiovisual da Escola de Música e Artes Cênicas da mesma instituição. wesleymax@gmail.com

${ }^{3}$ Prof. Ms. Cursos de Teatro/Licenciatura (presencial e EAD) e Direção de Arte/Bacharelado - Universidade Federal de Goiás (GO).guilhermeduca@gmail.com 
A utilização de recursos audiovisuais em espetáculos teatrais não é nenhuma novidade. Temos observado cada vez mais a inserção de vídeos (com ou sem áudio), projeção de fotos, desenhos, caricaturas, animações e imagens em geral em montagens que possuam como premissa o diálogo entre diferentes mídias e linguagens artísticas. Esta inter-relação, ao contrário de diminuir a importância da presença viva e pulsante entre atores e plateia, acaba por deixar mais complexa a situação de representação, uma vez que, em termos de narrativa, o que acontece no palco influencia o que está acontecendo no vídeo, e vice-versa.

Neste sentido, a montagem do espetáculo Enquanto Dure, no ano de 2015, pretendeu estabelecer uma profunda relação entre o audiovisual e o teatro, tendo ainda como parceira outra linguagem artística: a dança. Sendo assim, o projeto foi idealizado com a presença de três diretores, sendo cada um deles responsável por uma das principais formas artísticas do espetáculo. Naquela montagem, que se originou a partir da adaptação de um conto literário, foi experimentado o diálogo entre palco e vídeo, mesmo porque, no desenrolar das cenas da peça, o audiovisual entrava como complemento fundamental ao enredo, demonstrando situações obscuras entre os personagens, além de sonhos e devaneios.

Entretanto, ao final do projeto, ainda no ano de 2015, parte da equipe de produção sentiu-se desafiada a tentar buscar, através de outra montagem, novos tipos de relações interartísticas para a cena. Este anseio deu-se, em parte, por compreender que a experiência com o espetáculo Enquanto Dure ${ }^{4}$ havia permitido pensar múltiplas formas de utilização do audiovisual no teatro e, em outra medida, por considerar que, embora houvesse um resultado satisfatório dentro do que havia sido planejado para aquele espetáculo, o mesmo ainda não havia alcançado plenamente uma coesão em termos de diálogo entre cena e vídeo, deixando ainda uma espécie de sensação de compartimentação entre momentos de representação teatral e projeção audiovisual.

Tendo esta experiência como referência, propusemos, à época, a realização de um novo espetáculo, através de uma nova adaptação literária, na qual, além de estabelecer profundo diálogo entre palco e vídeo, buscaríamos nos utilizar de outro recurso teatral que, em sua essência, traz uma grande ligação com o cinema: me refiro ao Teatro de Sombras. Isto porque, nesta modalidade teatral, um tecido é utilizado no palco para que, através da incidência da luz de refletores especiais, atores, objetos e silhuetas sejam transformados em sombras projetadas na tela. Além de bidimensionalizar a imagem de seres tridimensionais, assim como o cinema, o teatro de sombras possui outros recursos que também são originários da sétima arte, como a possibilidade de zooms, travelings, diferentes ângulos e cores para as imagens, o que torna a experiência ainda mais rica do ponto de vista dos recursos audiovisuais.

A partir, então, da utilização de técnicas ligadas ao teatro, audiovisual e teatro de sombras, criamos o espetáculo Segredos e Sombras ${ }^{5}$ (2017), baseado no conto A

\footnotetext{
4 Enquanto Dure (2015). Espetáculo teatral livremente inspirando na obra Três nomes de Godofredo, de Murilo Rubião. Direção cênica: Alexandre Nunes. Direção coreográfica: Kleber Damaso. Direção audiovisual: Wesley Martins. Direção de Arte: Guilherme Oliveira. Elenco: Saulo Dallago e Andreydsa Luana Borges. Iluminação: Junior Oliveira. Trilha Sonora: Rogério Sobreira. Produção: Daniela Marques. Estreia em 16 de abril de 2015 no Centro Cultural UFG - Goiânia (GO).

5 Segredos e Sombras (2017). Espetáculo teatral baseado na obra A Causa Secreta, de Machado de Assis. Direção: Guilherme Oliveira. Elenco: Saulo Dallago, Vitória Santana e Wesley Martins. Iluminação: Edimar Pereira. Trilha Sonora: Rogério Sobreira. Produção: Jayla Siqueira Martins. Estreia em 04 de maio de 2017 no Centro Cultural UFG - Goiânia (GO).
} 
Causa Secreta, de Machado de Assis, montagem esta que, pelas características artísticas presentes em seu projeto, constituiu-se como inédita no estado de Goiás também única, por outro lado, por tratar-se da primeira adaptação do referido conto para os palcos em nossa região. Para este projeto, contemplado com patrocínio do Fundo de Arte e Cultura do estado de Goiás, foram mantidos, da equipe de produção do espetáculo Enquanto Dure, o diretor de audiovisual Wesley Martins, o ator principal e idealizador daquele espetáculo, o professor Saulo Dallago, e o diretor de arte, o professor Guilherme Oliveira. Além deles, a atriz e estudante do curso de Artes Cênicas da Universidade Federal de Goiás (UFG), Vitória Santana, completou a equipe principal da nova montagem.

\title{
O Visto e o não visto na cena iluminada
}

Pretendemos discorrer neste artigo sobre o processo de produção desta nova montagem, buscando descrever os desafios e possibilidades impostos pela relação cênica entre teatro convencional, audiovisual e teatro de sombras, tendo como eixo norteador da discussão a questão da iluminação cênica, componente plástico fundamental para harmonizar o jogo entre projeções, silhuetas, atores e elementos cênicos.

Em relação ao teatro de sombras, e mais especificamente ao chamado Teatro de Sombras contemporâneo, Fabrizio Montecchi nos dá algumas informações que permitem vislumbrar ainda mais aproximações entre esta modalidade do teatro de formas animadas e o cinema:

\begin{abstract}
Até o início dos anos Oitenta, na prática, todo o Teatro de Sombras (tradicional e não) baseava-se, embora com algumas declinações, na sombra obtida pelo contato direto da silhueta com a tela. Afastando a silhueta da tela, pelas características da fonte luminosa usada, a sombra perdia nitidez até não ser mais vista como a forma da figura que se desejava representar. Assim, o manipulador tinha sempre que agir próximo à tela. Com a introdução de uma fonte luminosa com filamento puntiforme, que permite obter sombras nítidas inclusive se a silhueta está afastada da tela, o Teatro de Sombras contemporâneo começou, por sua vez, a se utilizar de sombras projetadas. A cena, assim, transformou-se em um dispositivo de projeção que permitiu ao manipulador afastar-se da tela e agir no espaço, multiplicando as próprias possibilidades performáticas. (Montecchi, 2012, p. 27 e 28).
\end{abstract}

No conto A Causa Secreta, Machado de Assis procura explorar o relacionamento entre o médico Fortunato, sua esposa Maria Luísa e seu amigo e companheiro de profissão Garcia. Com o desenrolar do enredo, percebemos, principalmente através do ponto de vista de Garcia, que Fortunato parece esconder alguns segredos obscuros sobre sua personalidade, ao mesmo tempo em que um amor platônico parece brotar entre seu amigo e sua esposa. Machado, com maestria, vai nos apresentando acontecimentos envolvendo os três protagonistas, através de uma narração onisciente que, todavia, nos entrega os segredos dos personagens pouco a pouco. Em nossa montagem, pudemos dar voz aos três prismas dos protagonistas da história, demonstrando ao espectador um caleidoscópio de diferentes olhares sobre as peri- 
pécias envolvendo os mesmos. Utilizamos, para isso, recursos audiovisuais e de iluminação, principalmente através de técnicas do Teatro de Sombras, que, através do jogo com uma tela (tecido), parte do próprio cenário, e lanternas como refletores para a criação de sombras, permite o entrecruzamento entre imagens em duas dimensões (criadas com sombras e/ou projetadas a partir de vídeos) e três dimensões (os próprios atores, em cena, ao vivo, além de objetos e adereços).

Um dos primeiros passos na construção do espetáculo Segredos e Sombras foi, portanto, a definição de um ambiente cenográfico que melhor permitisse esta múltipla utilização em termos de linguagens visuais. Para tanto, levamos em consideração os três elementos essenciais no Teatro de Sombras: a fonte luminosa, o objeto interposto entre a luz e o suporte, e o suporte que recebe a luz e a sombra projetada - lembrando que a definição da sombra está atrelada à qualidade da fonte luminosa (que pode ser fixa em um ponto ou móvel), à materialidade do objeto e à sua distância em relação à fonte e ao suporte que recebe a sombra.

A base escolhida para o cenário foi uma estrutura metálica em formato de octógono, revestida lateralmente com tecido sintético próprio para cortinas, inicialmente branco, que seria utilizado como uma caixa cênica, separando a área de cena da audiência. Conforme o grau de iluminação em seu interior, ela permitiria ao espectador visualizar o que havia dentro, apenas a sombra dos corpos e materiais de cena ou ambos; quando a área do público estava iluminada, os atores conseguiam visualizar a plateia, mas esta não os enxergava, e isto se invertia quando a luz da plateia era apagada e iluminava-se o espaço cênico. Por outro lado, este mesmo cenário, por seu revestimento com tecido, permitia tanto sua utilização como suporte para sombras projetadas ao longo do espetáculo, tendo lanternas de led recarregáveis como fonte luminosa, quanto a projeção de vídeos a partir de um aparelho projetor de imagens.

Esta alternância entre o visto e o não visto (ou, antes, entre o que se ilumina e o que se obscurece) é determinante para a leitura simbólica de um espetáculo, visto que:

Diante dos diferentes aspectos da luz, o público de uma peça teatral pode enxergar elementos físicos e visuais e relacioná-los com as suas experiências pessoais, o que é determinante para sua compreensão da peça por meio da iluminação. (Assis, 2016, p. 22).

Entretanto, quando falamos em termos de iluminação cênica, nem sempre a intensidade da iluminação ou a claridade dos objetos cênicos estão diretamente relacionadas a uma melhor visualização, por parte dos espectadores, do espaço cênico. Isto foi descoberto na prática quando, ao iluminarmos o interior do cenário octogonal revestido por tecido branco e contando com móveis e objetos cênicos da mesma coloração (uma mesa, duas cadeiras, um gabinete e uma escada com 2 degraus) percebemos que o mesmo se tornou uma espécie de abajur: a luz rebatia nas laterais e nos objetos, ofuscando a visualização de quaisquer elementos ou atores no seu interior.

A combinação entre os tons e o contraste entre um tom e outro trazem noção de volume: um objeto branco dentro de um espaço branco, absolutamente sem contraste e variação tonal, tende a se confundir no conjunto e perder sua noção de volume. (Camargo, 2012, p.39). 
Diante disso, foram encontradas duas soluções: escurecer o tecido e os objetos cênicos, utilizando-se de materiais como betume, tintas e vernizes, para diminuir a reflexão da luz utilizada na cena, e direcionar os refletores para que não houvesse incidência direta de iluminação sobre os tecidos laterais do cenário, de forma a não causar o rebatimento da luz.

Observando a necessidade de não deixarmos a luz dos refletores banhar as paredes da cenografia, utilizamos os refletores de duas formas. Na primeira delas, fixamos os refletores de led na própria estrutura octogonal, sendo que suas carcaças ficavam visíveis para o público e tornavam-se parte da instalação cênica. A proximidade dos refletores com os atores e objetos de cena trazia uma qualidade distinta à cena, pelo ângulo em que a luz incidia sobre eles e pela qualidade fria da luz led. Quando os atores se aproximavam do tecido, seus corpos, em particular suas faces, refletiam mais intensamente a luz sobre a tela, gerando um halo em torno de suas imagens. Já em espaços onde era possível o uso de varas de iluminação, utilizamos preferencialmente os refletores com lâmpadas halógenas, como os elipsoidais, que permitiam recortes na luz, e outros refletores com auxílio de reguladores que delimitavam a área iluminada. A lâmpada halógena aceita melhor o processo de dimerização (ou seja, controle de intensidade através da mesa de luz) em comparação com o led; desta forma, a transição entre uma cena e outra era mais suave, especialmente quando optamos pelo uso da cor.

Escolhemos manter a maior parte das cenas em uma tonalidade âmbar claro, uma luz amarelada, em baixa intensidade. O uso de cores, como o azul e o vermelho, potencializava a dramaticidade das cenas por um lado, considerados os aspectos simbólicos e estéticos que a cor pode suscitar. Por outro lado, aos poucos fomos reduzindo a presença e a intensidade dessas cores, pois elas dificultavam a visualização do que havia no interior da cenografia.

A mesa, construída especialmente para utilização em cena, possui uma inclinação para que o público visualize melhor o que está sobre ela. Usada inicialmente como mesa de autópsia, num segundo momento, ela perde sua inclinação e é reposicionada cenicamente, se transformando em mesa de jantar. Ao final do espetáculo, retorna à posição inicial e seu tampo é levantado na inclinação máxima possível, tornando-se o esquife da personagem Maria Luiza e simulando ao público uma espécie de visualização aérea do corpo da personagem sobre o móvel. É importante ressaltar que ficavam ocultos, em sua base, diversos objetos de cena, como pratos, talheres, taças entre outros, além de, a partir de nossa segunda temporada de apresentações, uma caixa de som de onde saía a sonoplastia do espetáculo. Assim foi possível compor, com poucos elementos de cena, diferentes ambientes de acordo com a narrativa visual que se queria criar a cada momento da peça.

\section{O objeto cênico e seus significados a partir da iluminação}

No que diz respeito à iluminação da mesa, foram projetadas diferentes abordagens lumínicas para cada função cênica que a mesma ia assumindo ao longo da peça. 
Em diálogo com o iluminador do espetáculo, Edimar Pereira, três diferentes incidências de luz foram criadas para reforçar simbolicamente cada atribuição do objeto cênico: num primeiro momento, como mesa de autópsia, ganhou uma iluminação com luz a pino (vindo do alto da cabeça dos atores para baixo), recortada retangularmente de modo a criar um contorno de luz em toda a sua extensão (considerando seu tampo igualmente retangular); em seguida, ao se transformar em mesa de jantar, ganha uma iluminação um pouco mais incandescente, de forma a iluminar não só os atores que se posicionam junto à ela mas também os objetos e elementos dispostos sobre sua superfície; e, finalmente, em sua última função cênica, como esquife, foi posicionado um pequeno foco frontal, com o objetivo de iluminar o rosto do personagem/ cadáver Maria Luisa na cena final do espetáculo.

Além da mesa, os objetos relacionados à cena da autópsia e às refeições realizadas na casa do Médico Fortunato estabeleciam, por seus diferentes formatos, materiais e texturas, interações diversas com a luz. Objetos metálicos como pinças, facas e talheres refletiam a luz em cena com uma qualidade distinta daquela que advinha das taças translúcidas, ou seja, verificamos que, "a mesma luz, portanto, incidindo sobre superfícies distintas, produz diferentes tipos de reflexos" (Camargo, 2012, p. 57). Uma vez conscientes destas propriedades reflexivas e de como estes reflexos interagem com a cenografia, facilitando ou dificultando a visualização do que está em seu interior e agregando camadas de leitura à cena, procuramos ficar atentos à manipulação dos objetos e ao impacto destes sobre a composição das imagens que queríamos alcançar.

Pensado como parte de um teatro de formas animadas (que por sua vez, abarca também o Teatro de Sombras), o trabalho com objetos no teatro propõe constantemente a ressignificação dos elementos inanimados através da sua manipulação em cena. Assim:

\begin{abstract}
Vemos desenvolver-se, cada vez mais, um teatro experimental falando através de formas e objetos, concepções cênicas só possíveis com personagens não-humanos, ou protagonistas que não pretendem copiar o natural do homem. Formas e objetos, quando colocados fora de seu contexto e numa situação dramática, provocam estranhos insights. Um objeto qualquer de uso funcional, em cena, adquire um valor estranho e absoluto. Pode não se referir diretamente a deuses ou forças cósmicas, mas existe uma energia que exala da própria matéria. (Amaral, 2007, p. 60).
\end{abstract}

Após a primeira temporada do espetáculo Segredos e Sombras, realizada no ano de 2017, pudemos concretizar várias ideias cênicas que haviam servido como inspiração na proposição da montagem. Entretanto, como em quase todo processo criativo, sentimos que havia ainda outras possibilidades a serem investigadas, o que nos levou a planejar uma segunda temporada do espetáculo, proposta contemplada com patrocínio público da lei de incentivo municipal da cidade de Goiânia (GO). Neste sentido, na segunda temporada do espetáculo Segredos e Sombras, realizada em 2019, procuramos explorar não só a própria materialidade dos objetos em cena, mas cada vez mais os seus valores "estranhos e absolutos" a partir da projeção de suas sombras e da forma como eram iluminados. Indo além da proposição de trabalhar 
com o inanimado, seja fora ou dentro de seu contexto, buscando relações expandidas para estes objetos a partir da incidência da fonte de luz (lanternas e refletores) sobre os mesmos, criando imagens que estabelecessem relações de proximidade e estranhamento com seus suportes geradores.

Como exemplo, podemos citar a cena inicial do espetáculo, ligeiramente modificada a partir desta perspectiva. Na primeira versão do espetáculo (2017), a projeção da sombra do pé do suposto cadáver que ocupava a mesa de autópsia, realizada com uma lanterna de led como fonte luminosa, era a primeira imagem, materializada na região frontal do tecido do octógono cênico, recebida pelo espectador. Já na segunda versão (2019), antes de chegar ao pé, a luz da lanterna percorre, primeiramente, os cabelos da atriz que representa o cadáver, em seguida mostra o vão entre a estrutura metálica da mesa e o tampo onde se encontra o corpo, percorrendo este espaço até finalmente alcançar o pé. Este caminho percorrido pela lanterna, ressignifica os objetos (cabelo e vão da mesa) a partir de suas sombras e cria uma espécie de zona de indefinição para o espectador, pois não há certeza sobre o que está sendo iluminado/ projetado, até mostrar o pé, este sim plenamente entendido como o que realmente é; temos, assim, já na primeira cena da peça, uma trajetória que vai do inanimado para o humano, do objeto ao corpo, do abstrato ao concreto, do estranho ao conhecido.

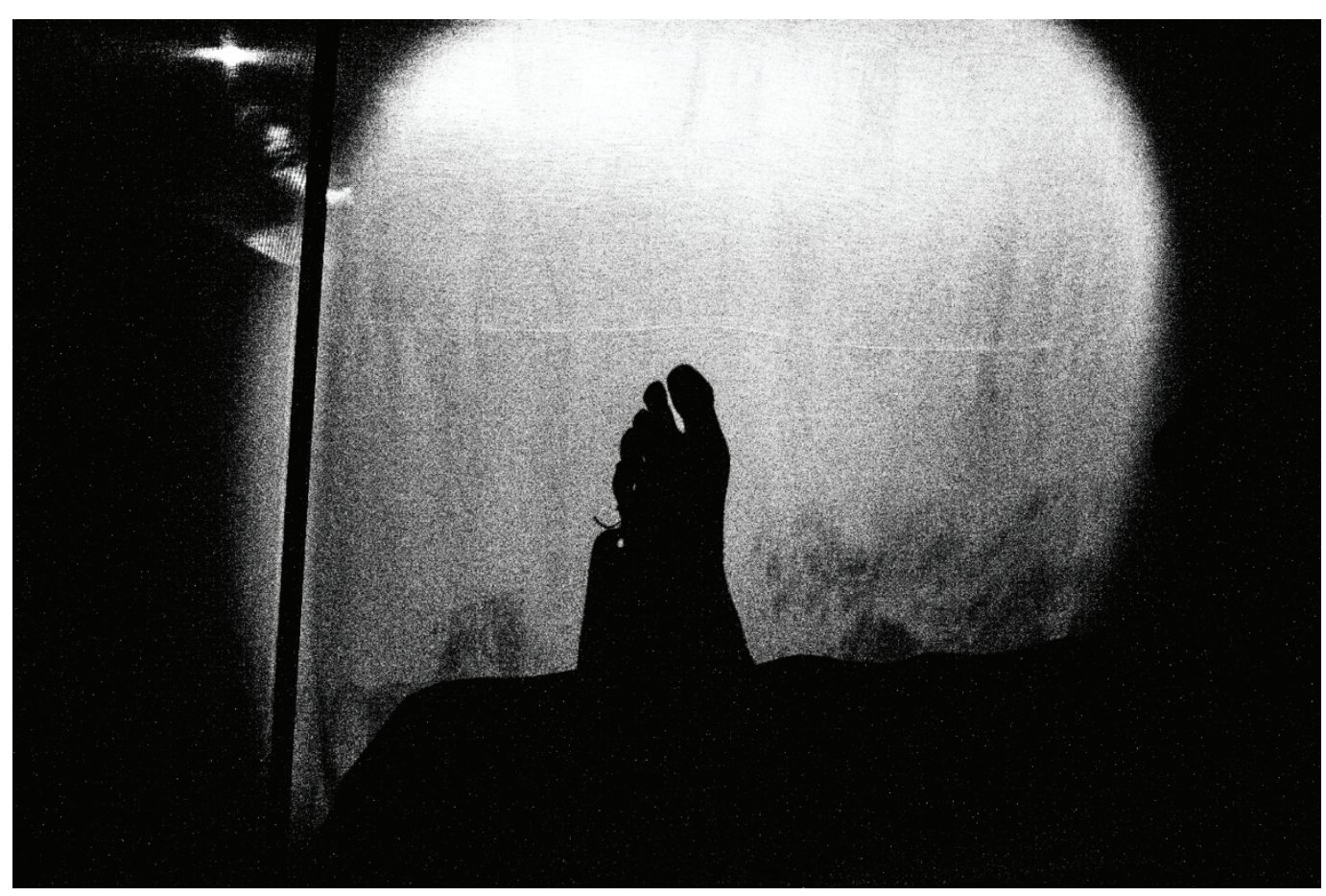

Figura 1 - Cena inicial do espetáculo Segredos e Sombras. Foto: Carlos Monareta.

Neste mesmo viés, a segunda temporada do espetáculo suscitou um olhar sobre a presença do ator em cena, sobre a possibilidade de utilizar a sua sombra como uma expansão do seu corpo, como suporte para a personagem e como meio para composição de uma dramaturgia da cena. Observamos que a presença do ator foi expandida, ainda que de forma multifacetada, posto que o tecido permitia a visualização da sombra corporal dos intérpretes e de seus corpos, ora simultaneamente, ora de forma alternada, isto é: conforme a incidência de luz sobre os atores e o tecido usado 
como suporte para as projeções, a plateia visualizava somente as sombras projetadas, as sombras e os corpos que as geravam, ou tinha como foco apenas os atores.

A ideia de expansão da presença do ator em cena que a sombra proporcionou no espetáculo Segredos e Sombras não ficou restrita à percepção do espectador em relação às sobreposições de imagens dos atores e de suas sombras nas diferentes faces do octógono que compunha a cenografia; os atores, com apoio da direção, passaram a ter que distinguir a imagem de seus corpos como materiais tridimensionais, que ocupavam uma espacialidade própria, dotada de peso e outros aspectos sensoriais, daquela imagem propiciada pela projeção de suas sombras. Mesmo que a cena tivesse por foco a sombra corporal do ator, era necessário um ajuste entre o tônus corporal, o tempo e o espaço, qualidades dadas ao movimento e à voz, ou seja, elementos próprios da interpretação que fossem condizentes com a composição visual e a leitura que se pretendia com as sombras projetadas.

Para Camargo, luz e cena atuam conjuntamente, uma afetando a outra: "Sem a luz, a cena não pode ser vista, e sem a cena, na sua materialidade, não há reflexos nem sombras" (2012, p. 29). Pensando sobre esta codependência entre luz e cena e tomando por base nossa experiência com o espetáculo, podemos nos indagar: existem diferenças quando o ator ilumina a si próprio com o objetivo de ser visto, projetando sua sombra e quando este é iluminado por outro ator ou pelo iluminador (fora da cena), para alcançar os mesmo fins? O que estas diferentes relações de iluminação da cena podem agregar ou demandar do trabalho do ator?

Observamos, por exemplo, que além das sombras criadas para e como cena, havia outras sombras presentes, sombras que escapavam ao controle dos atores e do diretor, podendo trazer novas leituras, nem sempre controláveis, aos espectadores. Compreendemos que seriam necessárias muitas temporadas e ensaios para termos uma ideia exata sobre a origem essas sombras, de quais fontes de luz vinham e em que ângulo eram projetadas, e que, mesmo assim, o seu completo domínio seria utópico. Buscamos, entretanto, reconhecer aos poucos a presença destas sombras incidentais, tentando agregá-las às narrativas propostas em cada cena.

\section{A auto iluminação cênica e o trabalho da cena}

Nesta segunda temporada, a auto iluminação em cena, ou seja, o próprio ator utilizar-se da lanterna de led para realizar a iluminação de seu rosto, partes do seu corpo, ou mesmo para projetar sua silhueta/sombra na cenografia, ganhou uma expansão em relação à primeira temporada, não só pela própria manipulação das fontes de iluminação pelos atores, mas também pelo fato de que as lanternas utilizadas na segunda temporada possuíam a ponta de seu cabo imantadas, o que possibilitou aos atores, em algumas cenas, colocar/grudar as mesmas em partes da estrutura metálica do octógono cenográfico, deixando suas mãos livres ao mesmo tempo em que auto iluminava-se a partir do posicionamento prévio da fonte de luz.

Os atores precisavam identificar em cada espaço teatral a forma como a luz iria incidir sobre a cena e, com base nesta percepção, realizar ajustes em suas marcações de cena. Esta integração dos intérpretes à iluminação se deu não apenas do ponto de vista das relações entre teatro de sombras e teatro tradicional, através da visualização 
da presença física dos atores por parte dos espectadores, mas também em diálogo com as intervenções audiovisuais propostas pela direção. Em uma das projeções externas de vídeos, com uma moldura circular e uma área central sombreada por edição, imagens de dissecção de ratos são sobrepostas com a imagem do personagem Fortunato (interpretado por Wesley Martins, ator que se auto ilumina com a lanterna no interior do octógono nesta cena). Conforme a distância e o ângulo do projetor, o ator flexionava os joelhos para ajustar sua altura à moldura por onde era visto, ao mesmo tempo em que iluminava a si mesmo. Na segunda temporada do espetáculo, adicionalmente, o ator passou também, na mesma cena, a mover a lanterna, criando, além da visualização de seu rosto e das imagens projetadas em torno de si, sombras que iam se modificando conforme se iluminava com a lanterna de diferentes ângulos, acentuando suas expressões faciais para o espectador.

Se pensarmos em um fio único onde a luz plena estivesse em uma ponta e a escuridão total estivesse na outra ponta, teríamos um espaço intermediário entre as duas, e ali encontramos os níveis de contraste que buscamos no espetáculo Segredos e Sombras. Iluminar esse espetáculo tem suas particularidades, inclusive entre os espaços de apresentação, pois a cada novo espaço, com diferentes estruturas de iluminação disponíveis, obtínhamos uma nova experiência. $O$ design da luz desse espetáculo vai além da iluminação cênica, se aproximando das características de outras formas de iluminação, como por exemplo a luz usada em museus.

Para realçar a visibilidade dessa obra, a quantidade de luz nela incidente terá de ser mais elevada, incrementando contraste para fazer sobressair em relação à parede de fundo. Mais luz significa maior dano e maior gasto energético. Inversamente, se as cores das paredes tiverem menor capacidade de reflexão (cerca de 40 a 50\%, com tonalidades intermédias), os desejados contraste e precisão visual serão atingidos com incidência de menor potência luminosa. (Vajão, 2015, p.101).

Esse contraste essencial para destaque da obra é também buscado no espetáculo. O cuidado de dimerizar a luz numa escala entre $40 \%$ e $60 \%$ na maioria das cenas passa justamente pela atenção dada à sua reflexão. Esses percentuais eram adaptados a cada apresentação, pois a iluminação base utilizada ainda eram os refletores aéreos do espaço cênico usado. Enquanto em alguns espaços as varas de luz eram fixas, em outros tínhamos a possibilidade de ajustar a altura e assim mudar o ângulo de incidência, a intensidade da luz, o tamanho do foco e até a quantidade de equipamentos a serem usados. O contraste necessário para que o público veja o que acontece na cena passa pelo balanceamento da intensidade, altura e quantidade de refletores. A partir de mais algumas observações do mesmo autor sobre a questão da luz em museus:

Este contraste relativo é mais evidente quando se recorre a projetores equipados com diafragma, que delimitam as projeções de luz aos extremos da pintura: como não há luz dispersa na parede adjacente, o contraste contra o fundo é muito maior à custa de quantidades de luz inferiores. $\mathrm{E}$ a área iluminada parece ter luz interior. Para além do ponto de vista estritamente luminotécnico, as cores das paredes têm a ver com a concepção plástica e 
arquitetônica do espaço, exigindo a intervenção conjunta dos responsáveis pela iluminação e pela decoração do espaço, para se alcançar a opção mais apelativa e conveniente. (Vajão, 2015, p. 101 e 102).

Pudemos analisar que este conceito de contraste também poderia ser usado neste espetáculo, nos trechos onde o teatro tradicional é a linguagem predominante em cena. Contudo, detectamos também uma diferenciação básica na questão do contraste de um museu dado pelo autor. A luz diafragmática (ou seja, com absoluto controle da profundidade de campo e quantidade de luz - tendo como base o diafragma de câmeras fotográficas) também pode ser utilizada no teatro, mas no museu, em casos gerais, as obras não se movem pelo espaço e o cálculo necessário é único. No espetáculo teatral, na maioria das vezes, os atores vão a procura da luz para obterem destaque. $O$ cuidado com a luz dispersa na apresentação teatral se torna uma necessidade essencial: sua entrada e saída tem que ter uma execução de maneira quase milimétrica, para que a dispersão não aconteça em áreas vazias, ou mesmo nas que não devam ganhar um destaque não condizente com a narrativa.

Outro fator a ser considerado é a reflexão do piso. A base da luz deste espetáculo teatral é feita na vertical ou na diagonal, dependendo da disponibilidade do espaço, mas sempre vinda de cima; sendo assim, se o piso é uma superfície pintada de tinta fosca ou brilhante, se é coberta com linóleo branco ou preto, amadeirado, encerado ou fosco, cada uma destas situações demanda adaptações e testes, com uma nova intensidade, cor e tamanho de foco da luz para a cena.

Como já explicado sobre a construção do espetáculo Segredos e Sombras, além da iluminação mais ligada ao teatro tradicional, temos também o Teatro de Sombras, que vai além de se ter simplesmente um personagem/ator iluminado. A expressão da luz se junta à expressão do personagem na construção da cena, como vemos na figura 2.

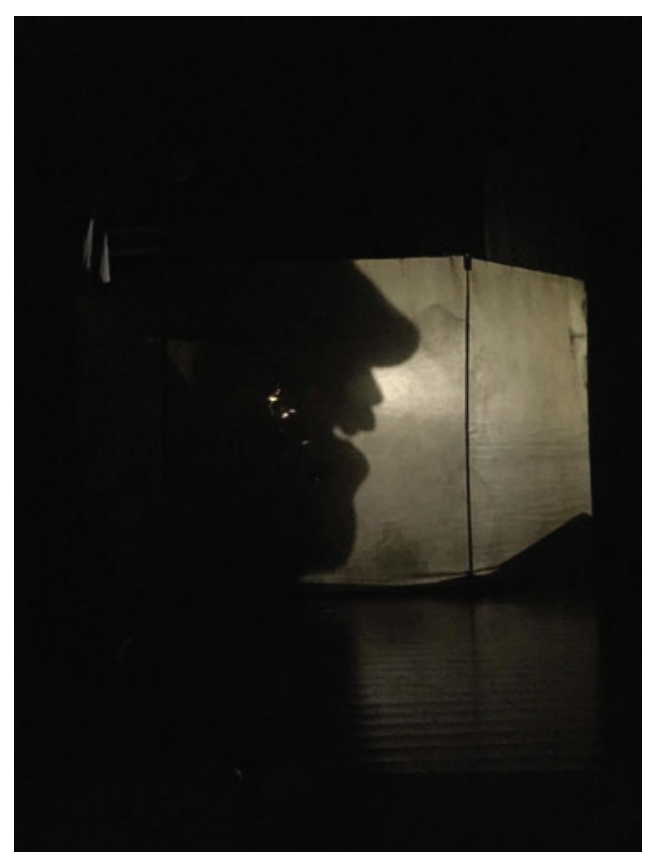

Figura 2 - Personagem: Fortunato. Foto: Jayla Siqueira. 
A luz no teatro busca definir e evidenciar a expressão da cena, e nisto se assemelha muito com o que o cinema faz em termos de composição imagética, ou seja: escolhe no que o público deve focar. Quando a luz está posicionada por trás do personagem/ator, ampliando suas feições, chamamos a sombra criada por esta iluminação de sombra de projeção, como definido por Richard Yot:

Existen dos tipos de sombras: las sombras de formas y las sombras de proyección. Las sombras de formas corresponden a las áreas sombreadas sobre una superficie a las que no puede llegar la fuente de luz. Las sombras de proyección son las que generalmente conocemos como sombras: las sombras proyectadas por un objeto sobre una superficie (como, por ejemplo, el suelo) cuando el objeto se encuentra entre la fuente de luz y dicha superficie. (2011, p.54).

Esses dois tipos de sombras elencados pelo autor podem ser explicados como as sombras de formas, que dão profundidade ao objeto ou espaço, e as sombras de projeção, aquelas que, conforme o nome indica, projetam o objeto em uma superfície. No espetáculo utilizamos as duas maneiras de se comunicar com a sombra, mas como dito pelo autor, somente a de projeção é mais conhecida como sombra. Com essa técnica conseguimos maior expressividade e qualidade de resolução das imagens criadas nas cenas, que forneceram subsídios ao público para identificá-las como condizentes com a trama. Um bom exemplo é a cena onde o personagem Fortunato toma o sangue de um rato (figura 3), demonstrando sua insanidade e crueldade.

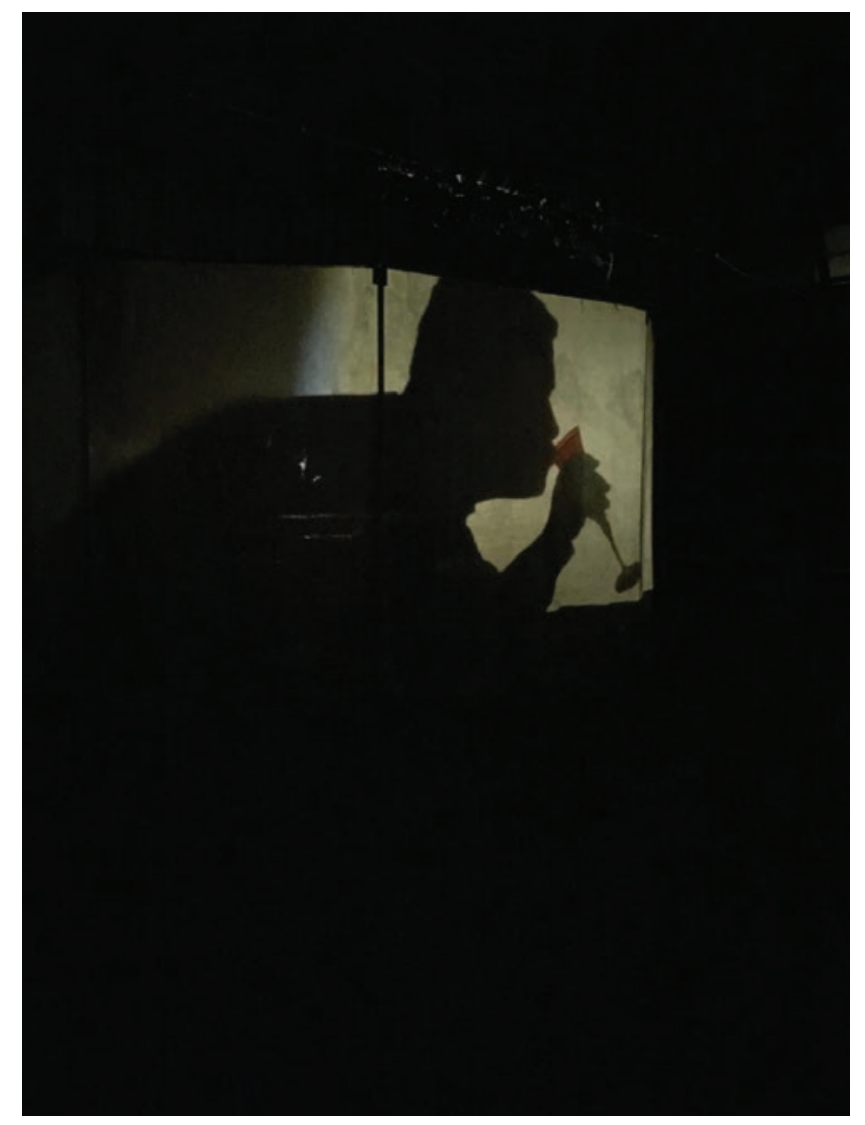

Figura 3 - Personagem toma o sangue de um rato. Foto: Jayla Siqueira. 
Observamos ainda nesta última figura que a sombra da taça tem cor vermelha; esse recurso está ligado a uma pesquisa realizada na produção do espetáculo entre a fonte luminosa, sua intensidade, distância do objeto, a transparência e a translucidez da taça. Sobre isso temos que:

La transparencia y la translucidez también pueden ejercer un impacto notable en el color de la sombra. Pueden afectar al color de dos formas diferentes. En primer lugar, el objeto que proyecta la sombras puede ser transparente o translúcido, como en el caso del cristal, por lo que, como consecuencia, dará lugar a una sombra de color. (Yot, 2011, p. 62).

Esse material da taça é translúcido e de cor vermelha, o que intensifica a cor da sombra. Entretanto, além do que é referido acima, tivemos também a inserção de líquido no recipiente, que teve a função de representação de sangue, principalmente na sua coloração. Nos testes realizados durante os ensaios, antes de escurecermos o ambiente e projetarmos a fonte luminosa (lanterna) para projeção da sombra no cenário (suporte), apenas água parecia suficiente para a função; todavia, ao acionar a lanterna, notamos que o efeito se anula, pois faltou o contraste necessário. Somente foi alcançado o efeito desejado utilizando um líquido com uma coloração mais escura que a água (utilizamos suco de uva). Assim, conseguimos colorir a sombra projetada em tonalidade diferente do vermelho, havendo contraste entre a cor do copo, do líquido e do personagem.

O uso da coloração na sombra foi empregado apenas em duas cenas: nesta citada e em uma segunda ocasião onde é representado um laboratório de experimentos médico-científicos. Constatamos a importância de iluminar objetos de conteúdos e superfícies coloridos nestes dois momentos, pois "al igual de lo que sucede con los sonidos y melodías, los colores son capaces de iluminar o ensombrecer nuestro estado de ánimo y de afectar nuestra subjetividad de muy diversas maneras" (Sirlin, 2006, p.125). O mesmo autor também defende, com base nos seus estudos, que a cor vermelha representa de forma direta uma ação violenta, justamente nossa intenção com a primeira das cenas.

A fonte de luz para produção destas sombras foram lanternas de led de tipo caça, tamanho pequeno (15 cm de comprimento e $4 \mathrm{~cm}$ de circunferência), recarregáveis. Sua estrutura de iluminação é muito similar a de um spot elipsoidal, onde um único filamento de led concentrado encontra-se no centro, com a parte interna feita de material refletivo e com um sistema óptico móvel que permite aumentar ou diminuir a circunferência e intensidade do foco. Essa é a segunda versão de lanternas utilizadas no espetáculo, e nos parece que cada vez mais esses equipamentos de iluminação conseguiram integrar aumento de potência com diminuição de estrutura. Contudo, sabemos que cada fonte luminosa sempre terá sua funcionalidade específica e que, mesmo com toda revolução tecnológica de equipamentos, uma simples vela poderá cumprir com os requisitos necessários de iluminação desejados no design da luz de uma cena.

Na montagem do espetáculo Segredos e Sombras pudemos experienciar diferentes efeitos de iluminação cênica, seja através de refletores com lâmpadas halógenas ou led, com lanternas e mesmo com a própria coloração da cenografia e objetos 
cênicos, imprescindíveis para obter a luminância almejada em termos estéticos. Por se tratar de um espetáculo que mesclava as linguagens do teatro tradicional, do teatro de sombras e do audiovisual, pudemos investigar materiais que tivessem flexibilidade e adequação às diferentes propostas cênicas utilizadas, e que, possivelmente, não seriam os mesmos caso a produção se referisse a apenas uma ou duas destas modalidades artísticas. A partir desta pesquisa, e do desenvolvimento de uma metodologia prática de trabalho, os desafios agora serão em torno de novas obras a serem produzidas: adaptando, criando e recriando estratégias de iluminação e projeção de sombras e imagens na montagem de outros textos, dramatúrgicos ou não, como no caso do conto A Causa Secreta, que nos proporcionou o desafio da criação da obra teatral Segredos e Sombras.

\section{Referências}

AMARAL, Ana Maria. Teatro de Animação. Cotia, SP: Ateliê Editorial, 2007.

ASSIS, Rodrigo. Design da lluminação: iluminação cênica de um espetáculo teatral. Goiânia: Gráfica e Editora América, 2016.

CAMARGO, Roberto Gill. Conceito de Iluminação Cênica: processos coevolutivos. Rio de Janeiro: Música e Tecnologia, 2012.

MONTECCHI, Fabrizio. Em busca de uma identidade: reflexões sobre o teatro de sombras Móin-Móin: Revista de Estudos sobre Teatro de Formas Animadas. Jaraguá do Sul: SCAR/UDESC, ano 8, v. 9, 2012 (2012, ps. 27-28).

SIRLIN, Eli. La luz en el teatro. Buenos Aires: Instituto Nacional del Teatro, 2006.

VAJÃO, Vítor. Manual de Práticas de Iluminação: arte a iluminar a arte. Lisboa: Lidel, 2015.

YOT, Richard. Guía para usar la Luz para ilustradores, dibujantes, pintores, interioristas y artistas. Barcelona: Art Blume, 2011.

Recebido em: 30/10/2019

Aprovado em: 09/12/2019 